\title{
ANALISIS NILAI TAMBAH BAWANG DAYAK (ELEUTHERINE AMERICANA MERR) MENJADI PRODUK OLAHAN STIK BAWANG DAYAK / LEMBA DI KELURAHAN KELAMPANGAN KECAMATAN SEBANGAU KOTA PALANGKA RAYA (STUDI KASUS INDUSTRI RUMAH TANGGA ROSSEMI)
}

\author{
${ }^{1}$ Muhamad Jaini, ${ }^{2}$ A. Zaki Yamani, ${ }^{3}$ Betrixia Barbara \\ ${ }^{1}$ Alumnus Program Studi Agribisnis Fakultas Pertanian Universitas Palangka Raya \\ ${ }^{2,}{ }^{3}$ Staf Pengajar Program Studi Agribisnis Fakultas Pertanian Univesitas Palangka Raya \\ Email: ahmad.zaki@agb.upr.co.id
}

\begin{abstract}
ABSTRAK
Penelitian ini bertujuan untuk (1). Mengetahui profil industri rumah tangga Rossemi, 2). Mengetahui proses pembuatan olahan Stik dari bawang dayak; dan 3). Mengetahui nilai tambah olahan Stik bawang dayak. Penelitian ini dilaksanakan di Kelurahan Kalampangan Kecamatan Sabangau Kota Palangka Raya. Industri rumah tangga pengolahan Stik Bawang Dayak "Rossemi' yang merupakan satu-satunya usaha industri rumah tangga yang berada di Kelurahan Kalampangan Kecamatan Sabangau Kota Palangka Raya. Untuk menjawab tujuan pertama dan kedua dilakukan dengan wawancara langsung dan pengumpulan data sekunder. Sedangkan untuk menjawab tujuan ketiga digunakan analisis nilai tambah dan deskriptif. Hasil penelitian ini yakni usaha industri rumah tangga rossemi ini memiliki potensi untuk dikembangkan dimana dilihat dari segi proses pembuatan yang mudah, bahan-bahan serta rempahrempah mudah didapatgkan. Sedangkan untuk menjawab tujuan ketiga mengetahui nilai tambah dari olahan stik bawang dayak yaitu mendapatkan keuntungan $\mathrm{Rp} 603.412 / \mathrm{Kg}$, dengan nilai tambah sebesar $\mathrm{Rp} 665.809$ per $\mathrm{Kg}$. Usaha ini sangat membantu sebagai usaha sampingan sebagai meningkatkan nilai tambah rumah tangga. Presentasi tingkat keuntungan usaha rumah tangga Rossemi ini sebesar 94.14\%. Dengan keuntungan yang cukup memadai sangatlah bermanfaat sebagai nilai tambah rumah tangga. Usaha ini sangatlah bagus untuk dikembangkan, selain sebai nilai tambah usaha ini juga dapat penciptakan lapangan pekerjaan bagi ibu-ibu rumah tangga sebagai nilai tambah ekonomi keluarga.
\end{abstract}

Kata Kunci: Nilai tambah, stik bawang dayak, potensi pengembangan.

\begin{abstract}
This study aims to (1). Knowing the process of making processed sticks from Dayak onions; and 2). Knowing the added value of processed Dayak sticks. This research was conducted in Kalampangan Village, Sabangau
\end{abstract}


District, Palangka Raya City. Home industry processing Dayak onion sticks "Rossemi" which is the only home industry that is located in Kalampangan Village, Sabangau District, Palangka Raya City. To answer the first and second objectives, direct interviews and secondary data collection were carried out. Meanwhile, to answer the third objective, a value added and descriptive analysis is used. The result of this research is that this rossemi home industry business has the potential to be developed which is seen in terms of an easy manufacturing process, ingredients and spices that are easy to obtain. Meanwhile, to answer the third objective, knowing the added value of processed Dayak sticks is getting Rp 386.194 / Kg of content, with an added value of $\mathrm{Rp} 386.194$ / Kg. This business is very petrifying as a side business to increase the added value of the household. The percentage of profit rate for Rossemi's household business is $57,92 \%$. with sufficient profit is very useful as an added value for the household. This business is very good to be developed, besides being an added value this business can also create jobs for housewives as an added value to the family economy.

\section{Keywords: Value added, Dayak sticks, development potential}

\section{PENDAHULUAN}

Penggunaan obat tradisional pada masyarakat Indonesia saat ini semakin berkembang. Banyak masyarakat tertarik untuk mengobati segala penyakit yang dideritanya dengan pengobatan tradisonal dari berbagai ragam tanaman obat-obatan. Salah satunya yaitu bawang dayak/lemba (Eleutherine Americana Merr), yang sudah dikembangkan khususnya di Kalimantan. Bulbus tanaman bawang dayak dipercaya sebagai tanaman obat multifungsi untuk berbagai penyakit. Tanaman ini memiliki warna umbi merah dengan daun hijau berbentuk pita dan bunganya berwarna putih. Bawang dayak yang berasal dari hutan Kalimantan memiliki khasiat dahsyat dalam pengobatan aneka penyakit. Namun, umbi ajaib ini belum banyak dikenal masyarakat luas sehingga baru sebagian saja yang memanfaatkan khasiatnya. Masyarakat dayak biasa menyebutnya dengan "bawang hutan atau bawang kambe". Jika masyarakat Melayu, mereka menyebutnya dengan "bawang mekah", mungkin karena khasiatnya yang ajaib. Tumbuhan ini sudah lama digunakan masyarakat setempat untuk pengobatan aneka penyakit. Kandungan senyawa aktif dalam bawang dayak sangat lengkap sehingga sangat wajar khasiatnya banyak. Dalam umbi bawang dayak terkandung senyawa fitokimia antara lain: alkaloid, glikosida, flavonoid, fenolik, streroid, dan tannin yang mana senyawa-senyawa tersebut diduga memiliki efek antimikroba. Bawang dayak telah diuji klinis di yayasan kanker Indonesia di Sidoarjo (Jawa Timur) tidak mengandung gula, ragi, penyedap, pewarna dan zat pengawet (aman konsumsi, alami tanpa efek samping) (Galinggung, 2007).

Tanaman ini mempunyai banyak jenis dengan bentuk yang beragam seperti bawang merah, bawang putih dan berbagai jenis bawang lainnya. Ciri spesifik tanaman ini adalah umbi tanaman berwarna merah menyala dengan permukaan yang sangat licin. Letak daun berpasangan dengan komposisi daun bersirip ganda. Tipe 
pertulangan daun sejajar dengan tepi daun licin dan bentuk daun berbentuk pita berbentuk garis. Selain digunakan sebagai tanaman obat tanaman ini juga dapat digunakan sebagai tanaman hias karena bunganya indah dengan warna putih yang memikat, dan bahwa bawang dayak dapat diolah menjadi bahan jajanan murah yang berkhasiat, misalnya mempergunakan bawang dayak sebagai bahan dasar pembuatan jajanan Stik Bawang Dayak. Makanan ini tidak mengandung bahan berbahaya dan ditambah lagi berkhasiat untuk kesehatan. Stik yang terbuat dari Bawang Dayak ini pun dapat dijadikan sebagai salah satu produk khas Kalimantan yang dapat dijadikan oleholeh bagi para wisatawan lokal maupun asing, walaupun di Kalimantan sendiri masih belum terkenal luas, dan produk ini juga bisa mengangkat keunggulan bawang dayak yang biasanya hanya digunakan sebagai obat-obatan.

Beberapa penelitian tentang bawang dayak telah dilakukan antara lain bulbus tanaman genus Eleutherine. Bulbus tanaman Eleutherine bulbosa dan Eleutherine americana diketahui mengandung senyawa metabolit sekunder golongan naftokuinon (elecanacin, eleutherin, eleutherol, eleutherinon) (Alvas, dkk, 2003). Banyak senyawa turunan naftokuinon diketahui memiliki bioaktivitas sebagai antikanker maupun antioksida, selain itu bersifat sangat toksit, umumnya digunakan sebagai antimikrobia, antifungal, antiviral dan antiparasit (Babula, dkk, 2005).

Prospek bawang sabrang atau bawang dayak sebagai tanaman obat untuk skala industri sangat besar, namun belum lengkapnya informasi mengenai teknik budidaya tumbuhan ini membuat sedikit terhambat penggunaanya sebagai bahan obat modern, oleh sebab itu pengembangan dalam budidaya tanaman ini sangat perlu dikembangkan (Anggraini, 2014).

\section{METODE PENELITIAN}

\section{Lokasi dan Waktu Penelitian}

Penelitian dilaksanakan di Jalan Manunggal RT 02, RW 02, No 12 Kelurahan Kelampangan Kecamatan Sabangau Kota Palangka Raya di ke diaman Ibu Rossemi/ Emi, pemilihan lokasi ini dilakukan secara sengaja (purposive), dengan pertimbangan di Kota Palangka Raya ini sangatlah jarang terlihat makanan ringan yang berkhasiat untuk tubuh manusia, dengan demikian Ibu Rossemi mendirikan sebuah usaha industri rumah tangga sebagai nilai tambah dengan mempergunakan Bawang Dayak sebagai bahan dasar pembuatan Stik Bawang Dayak yang belum pernah ditemui, maka dari itu jika makanan ringan ini akan menarik dimata konsumen. Selain itu, cemilan Stik Bawang Bayak ini tidak mengandung bahan berbahaya dan ditambah lagi berkhasiat untuk kesehatan. Waktu penelitian akan dilaksanakan selama 6 bulan dari bulan Maret 2020 sampai bulan Agustus 2020, dimulai dari peninjauan lokasi penelitian dan pengumpulan data sampai pada penulisan laporan akhir penelitian.

\section{Metode Pengumpulan Data}

Penelitian dilaksanakan di Jalan Manunggal RT 02, RW 02, No 12 Kelurahan Kelampangan Kecamatan Sabangau Kota Palangka Raya di ke diaman Ibu Rossemi/ Emi, pemilihan lokasi ini dilakukan secara sengaja (purposive), dengan pertimbangan di Kota Palangka Raya ini sangatlah jarang terlihat makanan ringan yang berkhasiat untuk tubuh manusia, dengan demikian Ibu Rossemi mendirikan sebuah usaha industri rumah tangga 
sebagai nilai tambah dengan mempergunakan Bawang Dayak sebagai bahan dasar pembuatan Stik Bawang Dayak yang belum pernah ditemui, maka dari itu jika makanan ringan ini akan menarik dimata konsumen. Selain itu, cemilan Stik Bawang Bayak ini tidak mengandung bahan berbahaya dan ditambah lagi berkhasiat untuk kesehatan. Waktu penelitian akan dilaksanakan selama 6 bulan dari bulan Maret 2020 sampai bulan Agustus 2020, dimulai dari peninjauan lokasi penelitian dan pengumpulan data sampai pada penulisan laporan akhir penelitian.

\section{Metode Analisis Data}

Data diperoleh dari hasil wawancara responden di lapangan diolah dan ditabulasi sederhana disesuaikan dengan tujuan penelitian. Pengolahan data kualitatif dilakukan dengan bantuan alat hitung atau komputer dan perhitungan disesuaikan dengan alat analisis yang digunakan. Data kualitatif diuraikan secara deskriptif artinya data tersebut akan diuraikan dan dijelaskan dengan kalimat yang baik dan benar guna memberikan gambaran yang lebih jelas tentang data tersebut.

Untuk menjawab tujuan penelitian pertama yaitu menjelaskan proses pembuatan Stik Bawang Dayak di Kelurahan Kelampangan Kota Palangka Raya, dengan menggunakan analisis deskriptif yang bertujuan untuk menggambarkan proses pembuatan Stik Bawang Dayak yang berada di Kelurahan Kelampangan Kota Palangka Raya

Analisis deskriptif kuantitatif digunakan untuk menjawab tujuan yang kedua yaitu menganalisis modal sekarang, biaya, penerimaan, serta keuntungan pedagang makanan jajanan olahan Stik Bawang Dayak di Kelurahan Kelampangan Kota Palangka Raya, dianalisis dengan rumus nilai tambah sebagai berikut:

Menurut Hayami dalam Akbar (2018), faktor-faktor yang mempengaruhi nilai tambah pengolahan dapat dikategorikan menjadi dua yaitu faktor teknis dan faktor pasar. Faktor teknis yang berguna adalah kapasitas produksi, jumlah bahan baku yang digunakan dan tenaga kerja. Faktor pasar yang berpengaruh adalah harga output, upah tenaga kerja, harga bahan baku dan nilai input lain selain bahan baku dan tenaga kerja. Nilai tambah merupakan metode yang digunakan untuk menganalisi nilai tambah yang dihasilkan dari Bawang Dayak yang diproses menjadi Stik Bawang Dayak. Metode Hayami digunakan untuk menghasilkan informasi seperti berikut:
a. Nilai perkiraan nilai tambah
b. Rasio nilai tambah terhadap output
c. Bagian tenaga kerja
d. Keuntungan yang diterima oleh suatu usaha
e. Imbalan untuk modal

Dengan kata lain nilai tambah menggambarkan imbalan bagi tenaga kerja, modal dan manajemen yang dapat dinyatakan secara matematis sebagai berikut:

Nilai Tambah $=\mathbf{f}(K, B, T, U, H, h, L)$

$\mathrm{K}=$ Kapasitas produksi

$\mathrm{B}=$ Bahan baku yang digunakan

$\mathrm{T}=$ Tenaga kerja yang digunakan

$\mathrm{U}=$ Upah tenaga kerja

$\mathrm{H}=$ Harga output

$\mathrm{h}=$ Harga bahan baku

$\mathrm{L}=$ Nilai input lain 
Tabel 3.1 Perhitungan Metode Hayami

\begin{tabular}{|c|c|c|}
\hline No & Variabel & Nilai \\
\hline & \multicolumn{2}{|l|}{ Output, Input, dan Harga } \\
\hline 1 & Output (bungkus/produksi) & (1) \\
\hline 2 & Input (kg/produksi) & (2) \\
\hline 3 & Tenaga kerja langsung (HOK) & (3) \\
\hline 4 & Faktor konversi & $(4)=(1) /(2)$ \\
\hline 5 & Koefisien tenaga kerja & $(5)=(3) /(2)$ \\
\hline 6 & Harga output & (6) \\
\hline \multirow[t]{2}{*}{7} & Upah rata-rata tenaga kerja (Rp/HOK) & $(7)$ \\
\hline & \multicolumn{2}{|l|}{ Penerimaan dan Keuntungan } \\
\hline 8 & Harga bahan baku (Rp/kg) & $(8)$ \\
\hline 9 & Sumbangan input lain (Rp/kg) & (9) \\
\hline 10 & Nilai output (Rp/kg) & $(10)=(4) x(6)$ \\
\hline \multirow[t]{2}{*}{11} & a. Nilai tambah $(\mathrm{Rp} / \mathrm{kg})$ & $(11 a)=(10)-(9)-(8)$ \\
\hline & b. Rasio nilai tambah (\%) & $(11 b)=[(11 a) /(10)] \times 100$ \\
\hline \multirow[t]{2}{*}{12} & a. Imbalan tenaga kerja $(\mathrm{Rp} / \mathrm{kg})$ & $(12 a)=(5) x(7)$ \\
\hline & b. Bagian tenaga kerja (\%) & $(12 b)=[(12 a) /(11 a)] \times 100$ \\
\hline \multirow[t]{3}{*}{13} & a. Keuntungan $(\mathrm{Rp} / \mathrm{kg})$ & $(13 a)=(11 a)-(12 a)$ \\
\hline & b. Tingkat keuntungan $(\%)$ & $(13 b)=[(13 a) /(11 a)] \times 100$ \\
\hline & \multicolumn{2}{|l|}{ Balas Jasa Pemilik Faktor Produksi } \\
\hline \multirow[t]{4}{*}{14} & Marjin (Rp/kg) & $(14)=(10)-(8)$ \\
\hline & a. Pendapatan tenaga kerja $(\%)$ & $(14 a)=[(12 a) /(14)] \times 100(\%)$ \\
\hline & b. Sumbangan input lain (\%) & $(14 b)=[(9) /(14)] \times 100$ \\
\hline & c. Keuntungan perusahaan & $(14 c)=[(13 a) /(14)] \times 100$ \\
\hline
\end{tabular}

\section{HASIL DAN PEMBAHASAN} Keadaan Usaha Industri Rumah Tangga Rossemi

Industri pengolahan bawang dayak menjadi stik bawang dayak ini berlokasi di jalan Manunggal RT.02 RW.02 NO.12 di Kelurahan Kalampangan Kecamatan Sabangau Kota Palangka Raya, usaha industri Rossemi ini berda di kawasan kebunkebun sekitar 300 meter masuk ke dalam, yang berada tepat disekitar pemukiman rumah warga setempat.

Alasan didirinya usaha industri rossemi ini karena sebagai ibu rumah tangga bagaimana caranya untuk mengisi waktu luang agar bisa mendapatkan penghasilan sampingan atau sebagai nilai tambah perekonomian rumah tangga.
Dengan seiringnya berjalan waktu pada tahun 2017 terpintas ide dari salah satu karyawan bernama Nursuraini (ibu nur) yang melihat tanaman obat-obatan (Biofarmaka) yang berada di samping rumahnya yaitu bawang dayak untuk mengolah bawang dayak/lemba menjadi sebuah olahan makanan ringan yaitu stik bawang dayak, karena mensgetahui bawang dayak sangat bermanfaat bagi kesehatan yang bisa digunakan sebagai obat herbal oleh masyarakat Indonesia khususnya Kalimantan, bawang dayak sangat efektif untuk mengobati penyakit seperti, tekanan darah tinggi, korestrol tinggi, diabetes, sembelit, batu ginjal, stroke, bahkan kanker.

Setelah menemukan olahan makanan ringan stik bawang dayak terbentuklah sebuah struktor organisasi usaha Rossemi yang beranggotakan tiga 
orang. Bisa dilihat pada Gambar 5.1 dibawah ini.

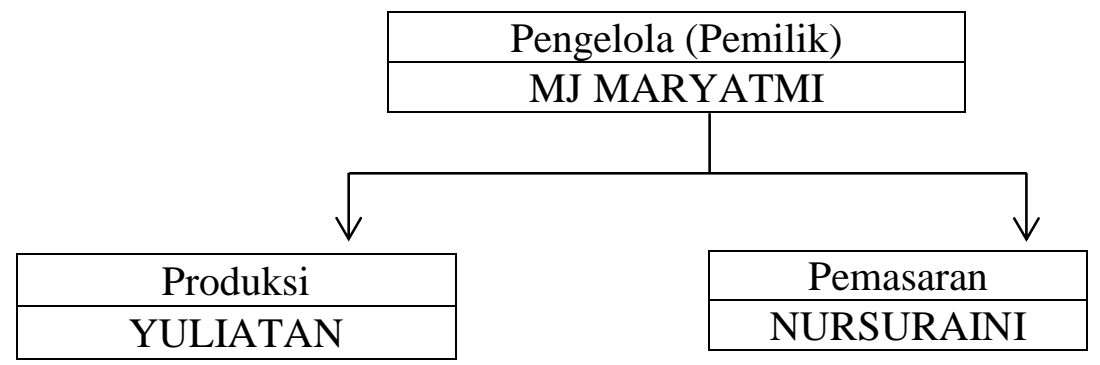

Gambar 5.1. Struktor Organisasi Industri Rumah Tangga Rossemi Sumber: Dokumen Pribadi Penelitian, 2021

Berdasarkan Gambar 5.1 dapat dilihat bahwa industri rumah tangga Rossemi Kelurahan Kalampagan Kecamatan Sabangau Kota Palangka Raya dipimpin oleh MJ Maryatmi/Ibu Emi, dan untuk tugas bagian produksi dikerjakan oleh Yuliatan/Ibu Yuli, sedangkan bagian pemasaran dipercayakan kepada Nursuraini/Ibu Nur.

\section{Tenaga Kerja}

Usaha industri rumah tangga Rossemi memiliki 2 orang karyawan yang bertugas masing-masing dibidang produksi dan pemasaran yang sudah ditentukan. Waktu jam kerja pada usaha industri rumah tangga Rossemi diatur oleh pemilik industri mulai pada pukul 08:00-13.00 WIB. Sistem upah kerja yang diberikan pada karyawan dihitung per produksi sebesar Rp 200.000,/orang. Cara pembayaran upah tenaga kerja dilakukan setiap kali produksi atau satu bulan produksi yang dilaksanakan.. Dimana produksi dilakukan 1 kali dalam satu bulan, waktu penyelesaian produksi masing-masing 4-5 jam.

\section{Produksi}

Dalam proses produksinya usaha industri Rossemi ini menngunakan bahan baku utama yaitu bawang dayak yang sudah dipilih kualitasnya. Bahan baku usaha industri rumah tangga
Rossemi ini di kebun sendiri di pekarangan rumah seluas $80 \mathrm{~m}^{2}$. Untuk sekali produksi bawang dayak sebanyak 4,5 Kg, setiap satu kali produksi yang dilaksanakan menghasilkan sebanyak 300 bungkus di mana satu bungkus beratnya sebesar 100 gram, dengan harga Rp.10.000,-.

\section{Pemasaran}

Dalam pemasarannya, usaha industri rumah tangga Rosemi hanya untuk pemesan seperti toko-toko yang berada di Kota Palangka Raya yaitu Indomaret, Bendara, Sendis, Hypermat dan Plut / KUMKM (kuliner khas Palangka Raya). Usaha industri rumah tangga Rossemi ini tidak menjual keliling, namun hanya menerima pesanan saja. Setiap kali produksi stik bawang dayak berbeda-beda jumlah yang dihasilkan, karena tergantug pesanan dari konsumen untuk tokoktoko di kota palangka raya yang dibutuhkan sebanyak 200 bungkus sedangkan untuk konsumen-konsumen lain sebanyak 100 bungkus untuk satu kali produksi. Total produksi stik bawang dayak dalam satu kali produksi sebanyak 300 bungkus pada bulan arpril 2020.

\section{Pendapatan}

Penerimaan yang diperoleh dalam 1 kali produksi pengolahan stik 
bawang dayak berkisar Rp 3.000.000,/satu 1 kali produksi. Dari hasil penerimaan tersebut digunakan kembali untuk biaya keperluan bahan-bahan untuk pembuatan stik bawang dayak, biaya trasportasi dan potongan gaji untuk karyawan berkisar Rp.700.000,-. Jadi pendapatan bersih yang diteri ma dalam satu bulan produksi pengolahan stik bawang dayak berkisar antara Rp.1.300.000,--

\section{Proses Pembuatan Olahan Stik Bawang Dayak}

Industri Rossemi didirikan oleh Ibu MJ Maryatmi/Ibu Emi pada tahun 2010. Sejak awal berdirinya industri ini sampai dengan sekarang terus melakukan produksi walaupun pada awal berdirinya industri ini melakukan berbagai macam jenis produk yang diolah hingga pada saat tahun 2017 industri rossemi ini mengolah bawang dayak menjadi stik bawang dayak, sampai dengan sekarang terus melakukan produksi. Tujuan dari berdirinya industri rumah tangga rossemi ini memiliki motivasi yang kuat untuk meningkatkan pemberdayaan perempuan yang ada di daerah sekitar agar dapat menambah pemasukan dalam ekonomi rumah tangga atau keluarga. Industri rossemi ini memiliki 3 orang pekerja, Ibu Emi sebagai pengelola atau pemilik usaha rossemi ini sedangkan dua karyawan lagi yaitu Ibu Yuli sebagai pemproduksi, sedangkan Ibu Nur sebagai pemasaran.

Dalam proses produksi Stik Bawang Dayak industri rossemi ini menggunakan bahan baku bawang dayak yang berkualitas baik. pasokan bahan baku industri rossemi ini berasal dari kebun sendiri tanpa harus mengeluarkan biaya yang besar untuk memenuhi bahan baku utama

Hasil olahan Stik Bawang Dayak yang diproduksi diIndustri Rossemi hanya memiliki satu variasi ukuran yaitu sebesar 100 gram dengan menggunakan kemasan standing pouch, berikut adalah proses tahap-tahap dalam pembuatan stik bawang dayak pada industi Rossemi adalah;

\section{Pemilihan Bawang Dayak \\ Untuk bawang dayak yang} berkualitas bagus berbentuk besar, tidak belubang, kulit mengkilat atau tampak licin merupakan tanda bahwa bawang dayak yang bagus. Jika bawang dayak tidak diolah langsung maka sebaiknya dianginkan dengan benar sehingga tidak mudah busuk. Jika warna kulit terluarnya merah gelap dan kusam, risiko cepat busuk juga semakin besar. Namun hal itu tidak akan terjadi diusaha industri rumah tangga Rossemi, karena jika mereka ingin mengolah stik bawang dayak maka hari itu juga mereka memanen bawang dayak yang mereka budidaya sendiri di pekarangan rumahnya, dengan itu kualitas bawang dayak akan sangat bagus jika langsung diolah dengan menghasilkan produk yang akan dihasilkan berkualitas sangat baik.

2. Pembersihan Bawang Dayak

Bawang dayak habis dipanen yang sudah dipilih dengan kualitas bagus, lalu dibersihkan dengan air keran dengan dibilas menggunakan tangan hingga bersih dari tanah-tanah dan kotoran lain yang menempel hingga bersih tanpa ada sedikitpun kotoran yang tersisa dibawang dayaknya, lalu dikeringkan beberapa menit sebelum dihaluskan menggunakan blender.

3. Penghalusan Stik Bawang Dayak

Bawang dayak yang sudah dikeringkan setelah dibilas lalu dihaluskan menggunakan blender listrik beberapa menit hingga benar-benar halus secara merata tanpa dicampurkan air.

4. Pengadonan 
Bawang dayak yang sudah dihaluskan dengan menggunakan blender listrik siap dicampurkan dengan bahan dan bumbu-bumbu lainnya seperti, tepung ketan, telur ayam, gula pasir, margarin, vanili, dan jahe yang sudah dihaluskan kemudian dicampurkan dengan bawang dayak yang sudah dihaluskan.

5. Pengolahan

Bawang dayak yang sudah dicampurkan dengan bahan atau bumbu-bumbu yang lainnya kemudian diaduk jadi satu dengan bahan atau bumbu-bumbu lainnya dengan menggunakan tangan agar bawang dayak dan bahan atau bumbu-bumbu lainnya benar-benar merata sampai mengental, padat dan menyatu.

6. Pencetakan dan Penggorengan

Terlebih dahulu siapkan alat pencetak stik adonan lalu panaskan minyak goreng dalam wajan setelah semuanya sudah siap, cetak langsung adonan didalam wajan berisi minyak goreng yang sudah panas sambil diaduk-aduk secara merata sampai berwarna kecoklatan yang menandakan stik bawang dayak sudah matang, lalu dingingkan selama kurang lebih 30 menit sebelum dikemas.

7. Pengemasan dan Penimbangan

Stik bawang dayak yang sudah didinginkan lalu dimasukan dalam kemasan yang sudah disediakan dengan bungkus kemasan yang sudah diberi label lengkap dengan komposisinya kemudian ditimbanng seberat 109 gram berat kotor bersama berat kemasan sebesar 0,9 gram, jadi berat bersihnya sebesar 100 gram kemudian selanjutnya stik bawang dayak ini ditutup dengan direkatkan menggumakan alat Hand Sealer kemudian stik bawang dayak ini siap untuk dijual.

\section{Analisis Nilai Tambah Bawang Dayak}

\section{Penyediaan Bahan Baku}

Berdasarkan hasil wawancara dengan responden di daerah penelitian, penggunaan bahan baku bawang dayak dalam industri pengolahan bawang dayak menjadi stik bawang dayak di Kelurahan Kalampangan Kota Palangka Raya dapat dilihat pada Tabel 5.2

Tabel 5.2 Rata-rata waktu pembuatan Bawang Dayak menjadi Stik Bawang Dayak dan Penggunaan Bahan Baku pada Indusri Pengolahan Bawang Dayak menjadi Stik Bawang Dayak Pada Bulan April di Kelurahan Kalampangan Kecamatan Sabangau Kota Palangka Raya Tahun 2020

\begin{tabular}{cccc}
\hline \multirow{2}{*}{ No. } & Uraian & \multicolumn{2}{c}{ Stik Bawang Dayak } \\
\cline { 2 - 4 } & Per Produksi & $\begin{array}{c}\text { Waktu Pembuatan Satu } \\
\text { Kali Produksi/ Jam }\end{array}$ & $\begin{array}{c}\text { Penggunaan Bahan Baku } \\
(\mathrm{Kg})\end{array}$ \\
\hline 1 & 5 & 4,5 \\
\hline \multicolumn{2}{l}{ Data Primer yang diolah, 2020 } & \multicolumn{3}{l}{}
\end{tabular}

Berdasarkan Tabel 5.2 di atas bahwa waktu rata-rata pengolahan bawang dayak menjadi stik bawang dayak dalam satu 1 kali produksi yaitu, dengan bahan baku yang digunakan rata-rata sebanyak 4,5 kg/produksi. Sedangkan waktu pembuatan selama 5 jam untuk satu kali produksi.

\section{Penggunaan Peralatan atau Modal}

Perencanaan pengadaan peralatan dari bahan baku yang efektif dan efisien dapat menjadikan kegiatan produksi 
berjalan lancar dan dapat meningkatkan hasil dan keuntungan bagi industri Rossemi. Rincian penggunaan peralatan

Tabel 5.3 Rincian Penggunaan Peralatan Pada Industri Stik Bawang Dayak Rossemi Kelurahan Kalampangan Kecamatan Sabangau Kota Palangka Raya Tahun 2020.

\begin{tabular}{clr}
\hline No. & Alat & Harga (Rp) \\
\hline 1 & Alat Cetak Stik & 35.000 \\
2 & Wajan & 30.000 \\
3 & Blender & 200.000 \\
4 & Baskom & 30.000 \\
5 & Timbangan & 60.000 \\
6 & Mangkok Pelastik & 10.000 \\
7 & Kompor Gas Satu Tungku & 200.000 \\
8 & Sendok Makan & 4.000 \\
9 & Spatula & 15.000 \\
10 & Serok & 15.000 \\
11 & Pisau & 10.000 \\
12 & Alat Pengepres Kemasan & 150.000 \\
\hline Jumlah & $\mathbf{7 5 9 . 0 0 0}$ \\
\hline
\end{tabular}

Data Primer yang diolah, 2020

Berikut Tabel 5.3 di atas rata-rata penggunaan modal yang dibutuhkan dalam menjalankan usaha pengolahan bawang dayak menjadi stik bawang dayak sebesar $\mathrm{Rp}$ 759.000, modal terbanyak untuk peralatan pembuatan stik bawang dayak adalah untuk pembelian blender yaitu sebesar $\mathrm{Rp}$ 200.000, sedangkan modal terkecil untuk yaitu satu buah sendok makan sebesar Rp 4.000. pada industri stik bawang dayak Rossemi dapat dilihat pada Tabel 5.3

\section{Penggunaan Tenaga Kerja}

Tenaga kerja yang bekerja pada industri pengolahan stik bawang dayak Rosemi berjumlah 3 orang yang berasal dari dua sumber yaitu, 1 orang dari dalam keluarga dan 2 orang dari luar keluarga. Biaya tenaga kerja pada industri Rossemi dalam satu kali produksi dapat dilihat pada tabel 5.4

Tabel 5.4 Penggunaan Tenaga Kerja Pada Industri Stik Bawang Dayak Rossemi Kelurahan

Kalampangan Kecamatan Sabangau Kota Palangka Raya Bulan April 2020

\begin{tabular}{ccc}
\hline \multirow{2}{*}{ Uraian } & \multicolumn{3}{c}{ Stik Bawang Dayak } \\
\cline { 2 - 3 } & Frekuensi Pembuatan & $\begin{array}{c}\text { Penggunaan Tenaga Kerja } \\
\text { (HOK) }\end{array}$ \\
\hline Per Produksi & 1 & 2,14 \\
\hline
\end{tabular}

Data Primer yang diolah, 2020

Dari Tabel 5.4, frekuensi pembuatan Stik bawang dayak adalah 1 kali dan penggunaan tenaga kerja 2,14 HOK, per bulan sebanyak 1 kali Produksi.

Dapat dilihat jumlah tenaga kerja pada industri Rossemi 1 HOK tenaga kerja perempuan dalam keluarga setara 5 jam kerja dalam satu kali produksi sedangkan 2 HOK tenaga kerja perempuan dari luar keluarga, dengan upah 1 HOK tenaga kerja dalam keluarga sebesar Rp 200.000 per 
produksi, sedangkan 2 HOK tenaga kerja dari luar keluarga sebesar Rp 400.000 per satu kali produksi, masingmasing satu orang tenaga kerja dari luar keluarga mendapatkan upah sebesar Rp 200.000 per $1 \mathrm{HOK}$. Sehingga industri usaha stik bawang dayak Rossemi mengeluarkan biaya untuk seluruh tenaga kerja dalam $3 \mathrm{HOK} / 1$ kali produksi pada bulan April 2020 sebesar Rp 600.000 per produksi.

\section{Input dan Output}

Input adalah penjumlahan bahan baku yang digunakan selama satu periode produksi untuk di prosesnya bawang dayak menjadi stik bawang dayak dan diukur dengan satuan $\mathrm{kg}$ bahan baku. Sedangkan output adalah jumlah produk yang dihasilkan selama satu periode produksi yang diukur dalam satuan bungkus produk. Rata-rata penggunaan bahan baku input dan output yang dihasilkan dari industri rumah tangga pengolahan stik bawang dayak Rossemi Kelurahan Kalampangan Kecamatan Sabangau Kota Palangka Raya, dapat dilihat pada Tabel 5.5.

Tabel 5.5. Penggunaan bahan baku input dan output yang dihasilkan dari industri rumah

tangga pengolahan stik bawang dayak Rossemi Kelurahan Kalampangan Kecamatan Sabangau Kota Palangka Raya Tahun 2020.

\begin{tabular}{ccc}
\hline Uraian & $\begin{array}{c}\text { Penggunaan bahan } \\
\text { baku/input }(\mathrm{Kg})\end{array}$ & $\begin{array}{c}\text { Output/produk yang } \\
\text { dihasilkan (Bungkus) }\end{array}$ \\
\hline Per Minggu & 4,5 & 300 \\
\hline
\end{tabular}

Data Primer yang diolah, 2020

Dapat dilihat pada Tabel 5.5 Bahan baku input dan output yang digunakan pada pembuatan stik bawang dayak menggunakan input bawang dayak sebanyak $4,5 \mathrm{~kg}$ dalam per minggu/produksi, dengan menghasilkan output 300 bungkus produk untuk satu kali produksi.

Tabel 5.6 Pengguaan input tambah untuk pengolahan stik bawang dayak Rossemi

Kelurahan Kalampangan Kecamatan Sabangau Kota Palangka Raya Tahun 2020

\begin{tabular}{clr}
\hline No. & & Bahan \\
\hline 1 & Gula Pasir & Harga (Rp) \\
2 & Tepung Ketan & 58.500 \\
3 & Plastik Kemasan Dan Stiker & 180.000 \\
4 & Telur Ayam & 450.000 \\
5 & Margarin & 250.000 \\
6 & Minyak Goreng & 5.000 \\
7 & Jahe Bubuk & 65.600 \\
8 & Vanili & 10.000 \\
9 & Garam & 30.000 \\
10 & Listrik & 3.000 \\
& & 23.000
\end{tabular}

\section{Input Tambahan}

Bahan baku penolong merupakan komponen terpenting nomor dua setelah bahan baku utama dalam pembuatan stik bawang dayak. Suatu produk tidak akan jadi jika bahan utama tidak ada, bahan penolong untuk menambahkan keefektifan hasil penggunaan produk.
Listrik 
11 Air

12 Sarung Tangan Plastik $\quad 3.000$

13 Biaya Penyusutan $\quad 28,524$

\begin{tabular}{lr}
\hline Jumlah & 1.082 .100 \\
\hline
\end{tabular}

\begin{tabular}{lr}
\hline Penggunaan Bahan Baku (kg) & $\mathbf{4 , 5}$ \\
\hline
\end{tabular}

Sumbangan Input Lain (Rp/kg)

240,466

Sumber: Data Primer yang diolah, 2020

Dapat dilihat pada Tabel 5.6

penggunaan input lain yang digunakan

pada pengolahan stik bawang dayak

biaya terbesar yang digunakan yaitu

plastik kemasan dan stiker sebanyak

200 lembar dengan biaya yang

dikeluarkan sebesar Rp 300.000,

sedangan biaya input lain yang paling sedikit yaitu pada pembelian margarin dan garam dengan biaya yang dikeluarkan sebesar $\mathrm{Rp}$ 2.000. Total biaya penggunaan input lain yang dikeluarkan dalam pembelian bahan input lain untuk pembuatan stik bawang dayak dan ditambah dengan biaya penyusutan yaitu sebesar Rp 572.617.

\section{Analisis Nilai Tambah Pengolahan Stik Bawang Dayak}

Nilai tambah merupakan selisih antara nilai produk olahan dengan biaya. Analisis nilai tambah dihitung untuk mengetahui pertambahan bawang dayak menjadi stik bawang dayak untuk menghitung nilai tambah stik bawang dayak tersebut digunakan analisis nilai tambah dengan menggunakan Metode Hayami. Sebagai mana hasil nilai tambah yang diperoleh industri stik bawang dayak Rossemi dalam satu kali produksi dapat dilihat pada Tabel 5.7

Tabel 5.7 Nilai Tambah Usaha Stik Bawang Dayak Rossemi Kelurahan Kalampangan Kecamatan Sabangau Kota Palangka Raya Tahun 2020

\begin{tabular}{|c|c|c|c|}
\hline No. & Variabel & Satuan & Stik Bawang Dayak \\
\hline & Output, Input, dan Harga & & \\
\hline 1 & Stik Bawang Dayak & Bungkus/Produksi & 300 \\
\hline 2 & Bawang Dayak & Kg/Produksi & 4,5 \\
\hline 3 & Tenaga Kerja & HOK/Produksi & 2,14 \\
\hline 4 & Faktor Konversi & - & 66.666 \\
\hline 5 & Koefesien tenaga kerja & - & 0,47 \\
\hline 6 & Harga Stik Bawang Dayak & Rp/Bungkus & 10.000 \\
\hline \multirow[t]{2}{*}{7} & Upah Tenaga Kerja & $\mathrm{Rp} / \mathrm{HOK}$ & 200.000 \\
\hline & Penerimaan dan Keuntungan & & \\
\hline 8 & Harga Bawang Dayak & $\mathrm{Rp} / \mathrm{Kg}$ & 40.000 \\
\hline 9 & Sumbangan input lain & $\mathrm{Rp} / \mathrm{Kg}$ & 240.466 \\
\hline 10 & Nilai Stik Bawang Dayak & Rp/Bungkus & 666.660 \\
\hline \multirow[t]{2}{*}{11} & a. Nilai Tambah & $\mathrm{Rp} / \mathrm{Kg}$ & 386.194 \\
\hline & b. Rasio nilai tambah & $\%$ & 57,92 \\
\hline \multirow[t]{2}{*}{12} & a. Pendapatan tenaga kerja & $\mathrm{Rp} / \mathrm{Kg}$ & 94.000 \\
\hline & b. Pangsa tenaga kerja & $\%$ & 24,34 \\
\hline \multirow[t]{3}{*}{13} & a. Keuntungan & $\mathrm{Rp} / \mathrm{Kg}$ & 292.194 \\
\hline & b. Tingkat keuntungan & $\%$ & 75,65 \\
\hline & Balas jasa pemilik faktor produksi & & \\
\hline \multirow[t]{3}{*}{14} & Margin & $\mathrm{Rp} / \mathrm{Kg}$ & 626.660 \\
\hline & a. Imbalan tenaga kerja & $\%$ & 15 \\
\hline & b. Sumbangan Input Lain & $\%$ & 91,55 \\
\hline
\end{tabular}


c. Keuntungan Pengusaha

$\%$ 46,62

Sumber: Data Primer yang diolah, 2020

\section{KESIMPULAN DAN SARAN}

\section{Kesimpulan}

Berdasarkan hasil dari analisis penelitian profil industri, proses pengolahan dan nilai tambah stik bawang dayak yang dimiliki oleh industri Rossemi.

1. Industri usaha stik bawang dayak Rossemi merupakan industri pengolahan bawang dayak menjadi sebuah olahan makanan ringan yang banyak mengandung khasiat bagi tubuh. Proses pembuatannya masih menggunakan peralatan tradisonal walapun pengolahannya yang tradisional karena kariyawan selalu menjaga kebersihan dan higienis. Pengolahan stik bawang dayak ini tidaklah sulit, dalam waktu kurang dari satu hari industri rossemi dapat menghasilkan 200300 bungkus,

2. Nilai tambah yang diperoleh usaha industri stik bawang dayak Rossemi adalah Rp 386,194. Nilai tambah diperoleh dari pengurangan nilai output (strik bawang dayak) dengan biaya bahan baku dengan sumbangan input lain. Sedangkan rasio nilai tambah sebesar $57,92 \%$, yang artinya $57,92 \%$ dari nilai output (stik bawang dayak) merupakan nilai tambah yang diperoleh dari pengolahan industri Rossemi.

\section{Saran}

Berdasarkan penelitian yang telah dilakukan, maka saran yang dapat dibeikan sebagai berikut :

1. Kepada pengusaha mendapat keuntungan yang maksimal, maka disarankan menambah olahan stik bawang dayak memiliki varian rasa, misalnya seperti stik bawang dayak rasa original, pedas, blado, dan asinan. Agar para pengensumsi tidak bosan dengan satu rasa saja, dengan demikian industi Rossemi juga mendapatkan nilai tambah lebih serta membuka lapangan pekerjaan bagi ibu-ibu lian.

2. Kepada pamerintah dinas terkait sebaiknya agar mendukung perkembangan industri pengolahan stik bawang dayak, memberikan penyuluhan mengenai inovasi baru tentang pengolahan, manajemen suatu industri yang tepat, serta menyediakan tempat serta perlengkapan pengolahan stik bawang dayak agar dapat meningkatkan pendapatan industri rossemi.

3. Kepada peneliti selanjutnya, diharapkan agar meneliti mengenai pendapatan hasil pertanian bawang dayak bukan hanya usaha industrinya.

\section{DAFTAR PUSTAKA}

Anggraini, Lili Tri. 2014. Pengaruh Jarak Tanam Dan Pembiaran Kompos Jerami Padi Terhadap Pertumbuhan Dan Produksi Bawang Dayak/Lemba (Eleutherine Americana Merr). Jurnal Online Agroteknologi. ISSN No. 2337-6597. Vol.2, No.3, Hal:974-981.

Babula V. Mikelova R, Patesil D, Adam V, Kizer R, Havel L, dan Sladky Z, 2005. Simultaneous Determination of 1,4- 
Naphtoquinone, Lawsone, Juglone and Plumbagin by Liquid Chromatograpy with UV Detection. Biomed paper. Vol. 149, No.1, Hal:25.

Galingging, R. Y. 2009. Bawang Dayak (Eleutherine Palmifolia) Sebagai Tanaman Obat Multifungsi. Diakses pada tanggal 10 januari 2013. http://Kalteng.litbang.deptan. go.id/ind/images/data/bawang \%20dayak.pdf. 